\title{
Adaptation to Climate Change: Threats and Opportunities for the Insurance Industry
}

\author{
Celine Herweijer ${ }^{\mathrm{a}}$, Nicola Ranger ${ }^{\mathrm{b}}$ and Robert E.T. Ward ${ }^{\mathrm{b}}$ \\ ${ }^{a}$ PricewaterhouseCoopers LLP, Sustainability and Climate Change Risk Advisory, 1 Embankment Place, \\ London WC2N 6RH, U.K. \\ E-mail: celine.herweijer@uk.pwc.com \\ ${ }^{\mathrm{b}}$ Grantham Research Institute on Climate Change and the Environment, London School of Economics and \\ Political Science, Houghton Street, London WC2A 2AE, U.K.
}

In this paper we explore why adaptation to climate change is such a critical issue to the commercial success of the private insurance industry. We highlight both the risks arising from inadequate adaptation to the impacts of climate change, and the opportunities presented by playing a role in the global response to adaptation. We demonstrate that the success, or not, of adaptation to the impacts of climate change will be relevant to both the underwriting and investment operations of (re)insurance companies. In the short term, climate change will affect underwriting practices by necessitating risk quantification approaches that include a forward-looking view of risk that is not purely grounded in historical experience. In the longer term, insufficient adaptation in areas of rising risk could threaten the concept of insurability itself, by limiting the availability and affordability of private insurance coverage. Furthermore, we demonstrate that activities that incentivise and enable adaptation not only give rise to commercial opportunities and reputational reward, but are increasingly necessary for the sustainability of the industry.

The Geneva Papers (2009) 34, 360-380. doi:10.1057/gpp.2009.13

Keywords: adaptation; climate change; insurance; insurability

\section{Introduction}

Managing the risks from climate change requires urgent action both to mitigate atmospheric greenhouse gas levels through reducing global emissions and to adapt to the changes in climate at a local level to minimise risks and maximise potential opportunities. The insurance industry can have an important role to play in both of these responses. Adaptation, or lack thereof, is particularly critical to the insurance industry as it directly affects the very core of their property and casualty businesses; the risk landscape that they insure and the concept of "insurability" itself. This paper highlights the business case for the private insurance industry to proactively support adaptation, through both implementing adapted underwriting and asset management approaches in their internal business practices, and by helping to promote adaptation at a societal level. The second part of the paper will focus on how the industry can seize opportunities from adaptation and gives best practice examples. 


\section{Climate change, risk and insurability}

Climate change is both a possible near-term and long-term threat to the insurance industry, potentially impacting underwriting, asset management and business strategy.

\section{Climate change and today's underwriting practices}

The insurance industry has traditionally based its view of risk on historical records of hazard occurrences. The most significant near-term threat to the industry's property and casualty businesses stems from the potential for the characteristics of the insured weather hazards to differ from those of the past as a result of climate change; if this statistical non-stationarity in hazard cannot be adequately anticipated by an insurer through their underwriting practices (in particular, the pricing and diversification of risk across a portfolio) and in their risk capital reserves, then it could undermine the financial stability of their organisation.

The impacts of unexpected changes in weather hazards on the insurance industry are demonstrated over the last 20 years in the provision of coverage against wind damage by hurricanes along the Atlantic and Gulf coastlines of the United States. In 1992, Hurricane Andrew hit south-eastern Florida as a category 5 storm, causing \$22.3 billion in insured damage in 2005 U.S. $\$ .{ }^{1}$ Nine insurers were made insolvent as a result of their losses because they had based their underwriting practices on the immediate previous experience of claims (e.g. over the preceding 30 years), which had not included an event of the magnitude of Hurricane Andrew. ${ }^{2}$ In addition to insolvencies, the hurricane had a dramatic effect on the subsequent affordability and availability of coverage against wind damage, particularly for homeowners.

It is now recognised that Hurricane Andrew occurred during a period of relatively low annual frequency of tropical cyclones in the North Atlantic between 1970 and 1994 (Figure 1). This coincided with a period of rapid population growth along many

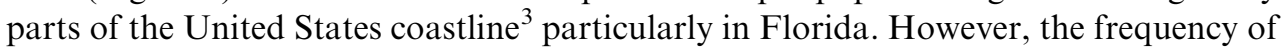
hurricanes increased markedly after 1995, a shift that was largely unanticipated by property developers and owners, policy-makers or the insurance industry. Although the particularly active seasons in 2004 and 2005, when a total of eight hurricanes struck the Gulf and Atlantic coasts of the United States, did not have the same devastating effect on the insurance industry as Hurricane Andrew, they resulted in coverage for many properties being either withdrawn or increased in price. This has led to much debate between homeowners, their political representatives and the industry about the affordability and availability of coverage.

While it is not clear to what extent the increase in the frequency of tropical cyclones in the North Atlantic (Figure 1) might be attributable to climate change, it has illustrated the potential consequences of future unanticipated changes in weather hazards.

\footnotetext{
${ }^{1}$ Swiss Re (2006).

${ }^{2}$ Grossi and Kunreuther (2005).

${ }^{3}$ Pidot (2007).
} 


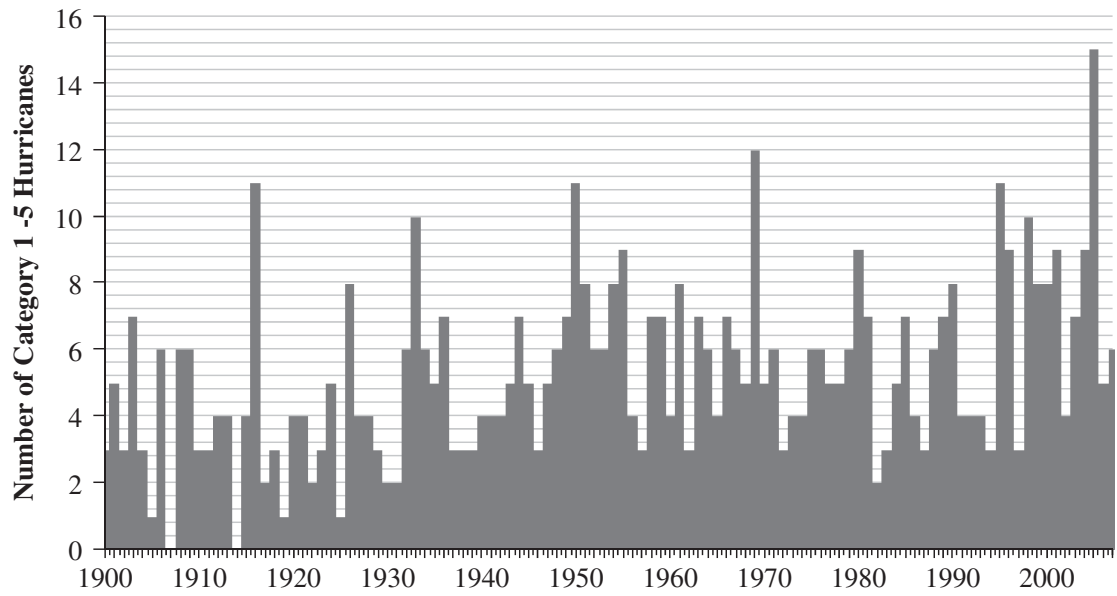

Figure 1. Atlantic basin hurricane rates 1900-2007 based on NOAA Hurdat data.

Globally, there are signs of statistically significant non-stationarity in other hazard characteristics, for example, the frequency of heavy rainfall. ${ }^{4}$ However, for many hazards of relevance to the insurance industry, statistically robust local trends are not yet observed. Nonetheless, it is widely expected that climate change will lead to significant shifts in the frequency, intensity and geographical distribution of extreme weather events (though the exact nature and scale of these shifts, in many cases, remains highly uncertain).

The risk assessment tools used by insurers in their underwriting must take into account any non-stationarity to ensure that their estimates accurately reflect any changes in risks today. Catastrophe risk models, like those produced by Risk Management Solution (RMS), have been extensively used by the insurance industry for the purpose of assessing and managing risk since Hurricane Andrew demonstrated the shortcomings in underwriting practices that were based solely on immediate past experience. For RMS, detecting and incorporating any statistically significant nonstationarity into its "medium-term" (1-5-year) future view of risk is a crucial component of the development process for all new models. The use of such tools will likely become increasingly important in insurance risk management as hazard characteristics move further away from historical experience.

\section{Climate change impacts on long-term insurability}

In the longer term, the nature of the key threats from climate change to the insurance industry will very likely depend on the market in which private insurers and reinsurers operate. Crucially, climate change has the potential to threaten the widespread

${ }^{4}$ IPCC (2007). 
availability and affordability of insurance for people and their property in many regions, that is, the insurability of the risk.

Insurability depends on a number of criteria, including actuarial, market-based and societal factors, many of which may potentially be affected by climate change (Table 1). In particular, it is currently difficult to estimate exactly how climate change will affect future weather hazards locally, leading to additional uncertainty about the frequency and magnitude of potential losses. Similarly, any increase in the frequency and/or intensity of weather hazards would mean that the consequent average and maximum losses would increase. For example, a recent study by RMS and Lloyd's of London indicated that sea level rise could drive a doubling of average annual losses (AALs) from storm surge for individual properties in the most exposed coastal areas by the 2030s, and around a 10-20 per cent increase in 1-in-200 year losses. ${ }^{5}$ Research by the Association of British Insurers in 2005 concluded that with a 6 per cent increase in wind speeds, AALs from hurricane damage in the United States would increase from US\$5.5 billion to around 'US\$9.5 billion, and 1-in-250 year losses from' US $\$ 85$ billion to $\$ 150$ billion, from currently existing properties. ${ }^{6}$

An increase in the magnitude or frequency of weather hazards with future climate change could also lead to an increase in the risk of correlated losses, for instance from coastal or inland flooding. In the United States, private insurers have largely refused to offer policies to cover flood damage to homeowners since the 1920s, after recognising the risks of large correlated losses from events along major waterways, such as the Mississippi River, eventually leading to the advent of the state-funded National Flood Insurance Program in $1968 .^{7}$ In addition, more large "super catastrophes" could result in correlated losses across business lines, coverages and perils, while an increased correlation between climate events across geographically diverse locations could arise from correlation with a latent variable, such as sea level rise or warmer tropical oceans.

Such increases in expected losses due to climate change would have profound consequences for the future affordability and availability of cover. Recent evidence from the United States suggests that such major changes in policies offered by private insurers to cover homeowners' properties, particularly if introduced relatively rapidly, can create negative public and political reactions. Insurers may find that other parts of their businesses can be affected by public and political dissatisfaction - in Florida, for instance, regulators have attempted to prevent private insurers from withdrawing coverage for wind damage by making licences to write automobile policies contingent on maintaining adequate provision of homeowners' property insurance. This suggests that the insurance industry is likely to face increased regulatory scrutiny and action if it does not respond appropriately to the threat of rising uninsurability. ${ }^{8}$ Moreover, an increase in the proportion of properties that are uninsurable potentially threatens the viability of the private insurers, as it could lead to

\footnotetext{
${ }^{5}$ Lloyd's of London (2008).

${ }^{6}$ ABI (2005).

${ }^{7}$ Kunreuther and Pauly (2009).

${ }^{8}$ See for example: National Association of Insurance Commissioners (2008).
} 
The Geneva Papers on Risk and Insurance - Issues and Practice

364

Table 1 Criteria for insurability and impacts of climate change ${ }^{9}$

\begin{tabular}{|c|c|c|c|}
\hline Category & Criterion & Characteristic & $\begin{array}{l}\text { Impacted by climate } \\
\text { change? }\end{array}$ \\
\hline \multirow[t]{6}{*}{ Actuarial } & Risk/uncertainty & Measurable & Yes \\
\hline & Loss occurrences & Independent & Possibly \\
\hline & Maximum loss & Manageable & Likely \\
\hline & Average loss & Moderate & Yes \\
\hline & Loss frequency & High & Yes \\
\hline & Moral hazard, Adverse selection & Not excessive & Unlikely \\
\hline \multirow[t]{3}{*}{ Market-determined } & Insurance premium & Adequate, Affordable & Yes \\
\hline & Insurance cover limits & Acceptable & Possibly \\
\hline & Industry capacity & Sufficient & Yes \\
\hline \multirow[t]{2}{*}{ Societal } & Public policy & Consistent with cover & Likely \\
\hline & Legal system & Permits the cover & Unlikely \\
\hline
\end{tabular}

Columns 1 to 3 (from the left) are reproduced from Swiss Re and present the central criteria of insurability and their characteristics that would make a risk insurable (e.g., risk should be measurable). The final column indicates whether the characteristics of the criteria will be affected by climate change, based on current scientific understanding and experience.

a reduction in the overall number of policies that are sold. Such a contraction might initially have a relatively small effect on the insurance companies if they are able to find new customers to replace those considered to be uninsurable. However, this may be a limited option in relatively mature markets with high rates of insurance penetration.

\section{Adaptation decision making under uncertainty}

Some impacts from climate change are quite certain in their direction (sea levels will rise, global temperatures will warm), others are less clear (e.g. we do not know how rainfall will be affected in some regions), and the finer the geographical scale, the more uncertainty there is. This poses a problem as investment in adaptation requires anticipating climate change impacts at a local level, and there is large uncertainty in future climate change at this scale. Furthermore, in some circumstances an inadequate adaptation strategy can present a worse outcome than a no-adaptation strategy. Such uncertainty is not going to be removed in the coming decades as the climate system is inherently chaotic and even the development of increasingly more powerful computer models will not be able to remove all uncertainty. Therefore risk managers must plan flexibly to allow for the unexpected. Where possible, adaptation decisions must also be made to be robust to most possible changes in climate conditions. An example of a robust solution may include identifying no-regret strategies that bring benefits even in absence of future climate change (e.g. improved building codes and limiting development in high risk areas).

\footnotetext{
${ }^{9}$ For a more detailed discussion of the 11 criteria, see Swiss Re (2005), Table 1.
} 
Investors and other fiduciaries across the business community are increasingly being advised to assess their portfolios for climate change risk. This trend is accompanied by substantial increases in the level of concern among institutional investors - and intervention - with the impact of climate change risks on their investee companies. ${ }^{10}$ The formation of the Carbon Disclosure Project (CDP), the Investors' Network on Climate Risk (INCR), and the Institutional Investor Group on Climate Change (IIGCC) highlights the growth of interest among institutional investors. In total, these groups represented combined assets of over $\$ 47$ trillion in 2007. From the perspective of climate risk assessment, the CDP requests companies to disclose the risks and opportunities for their operations from the physical impacts of climate change, while in early 2008, the INCR signed up to a "climate risk action plan" which pledges to require asset managers, consultants and advisors to screen their investment processes for climate risks.

With more than \$16 trillion in funds under management, the global assets of the private insurance industry will also have substantial exposure to future climate risk. The physical impacts of climate change, and the success or not of any adaptation, will directly impact the investment arms of insurance and reinsurance companies. It should be recognised that risk assessments of an insurer's investment portfolio need to incorporate an analysis of the impact of climate change. It is important for asset managers not only to identify the companies whose operations and performance are particularly vulnerable to the impacts of climate change, but also to strategically target those that are particularly resilient. Such screening is particularly important for real estate and other climate-sensitive sectors, municipal bonds and infrastructure funds. In each case, asset managers must ensure that their investments are resilient to climate change over their invested lifetimes. Historically, risk assessments have not adopted such a forward-looking approach, and have tended to be based on assumptions that climate risks are stationary through time.

Incorporation of climate change into investment strategies is a key principle of the ClimateWise initiative, to which more than 40 leading companies and organisations in the insurance industry have signed, to demonstrate leadership on climate change and to disclose their related actions. The 2007 annual review of ClimateWise revealed that, of the 41 members, 20 companies had taken climate change into account in their investment strategies, but only three had undertaken a review of their portfolios to consider where climate risk would have implications for the value of their investments. One signatory, AXA, stated that it believes that climate change presents material risks and opportunities for companies across a wide range of sectors, and that it carries out research to create and analyse climate change diagnostics of investee companies. $^{11}$

\footnotetext{
${ }^{10}$ Sullivan et al. (2008).

${ }^{11}$ Forum for the Future (2008).
} 


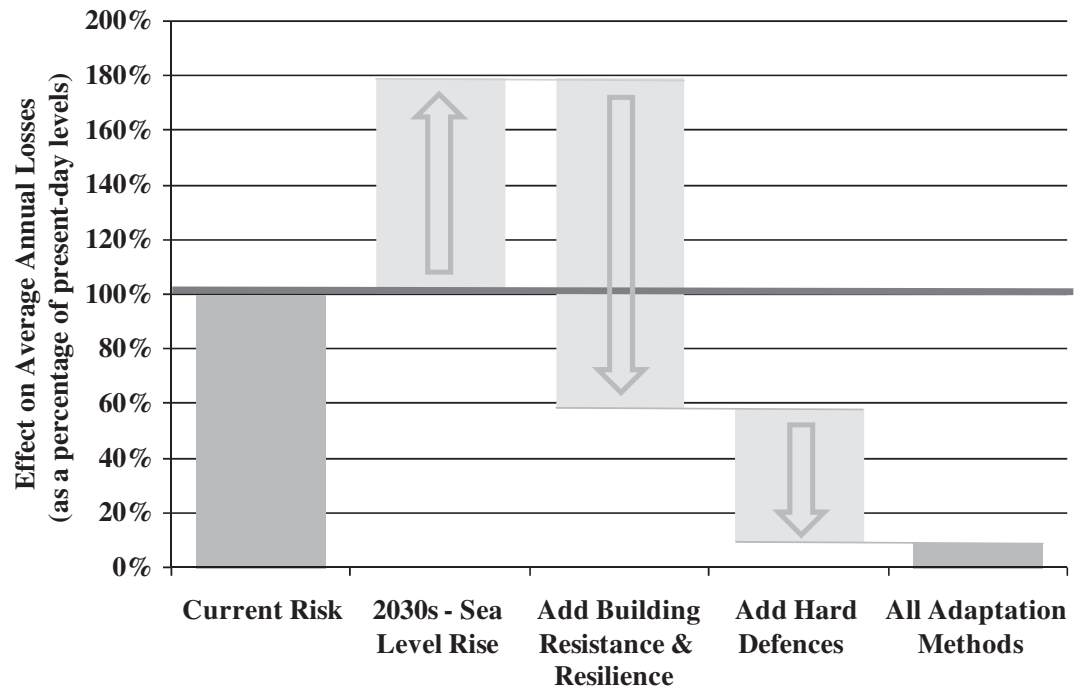

Figure 2. An example of the impacts of sea level rise on average annual losses from storm surges in high risk coastal areas in the U.K. and the loss reduction benefits of adaptation (building more resilient and resistant buildings and hazard defences). Figure reproduced from Lloyd's of London (2008).

\section{The business case for (re)insurer involvement in adaptation}

In the opening section, it was noted that climate change could significantly increase insured losses due to weather hazards. However, such losses can be limited by adapting properties to better withstand damage from such hazards. Successful adaptation will be fundamental to maintaining and extending insurability both in the existing and emerging markets. For example, in the recent project undertaken by RMS with Lloyd's of London ${ }^{12}$, it was shown that adaptation could reduce average annual losses from storm surge for individual properties in high-risk coastal communities in the 2030s to below present-day levels.

Losses with higher return periods can also be significantly reduced, lowering the risk. For example, the Association of British Insurers ${ }^{13}$ demonstrated that investments to improve flood defences along the U.K. coast over the coming decades (on a par with those suggested in Government plans), could reduce losses from a major storm surge (200-250 year return period) in the 2080 s from $£ 8-£ 16$ billion to $£ 4-£ 7$ billion. Such findings demonstrate the large benefits that the insurance industry can gain from adaptation (see Figure 2).

\section{Adaptation opportunities for the insurance industry}

The preceding section has outlined the threats that the insurance industry faces if society does not adequately adapt to impacts of climate change. The fundamental

\footnotetext{
${ }^{12}$ Lloyd's of London (2008).

${ }^{13}$ Association of British Insurers (2005).
} 
requirement to maintain insurability in the long term makes successful and timely adaptation a necessity, along with the social implications for vulnerable non adapted communities. The key question thus becomes the following.

\section{What can the insurance industry do to support and promote societal adaptation?}

In this section, adaptation opportunities for the insurance industry will be discussed in relation to both property and casualty businesses in the insurance markets of developed countries, and the emerging or potentially emerging markets in developing countries. It will be shown that adaptation can provide the private insurance industry with new business opportunities, as well as reputational benefits.

\section{Core insurance markets}

Adaptation (or risk mitigation) can have significant benefits in terms of helping existing private insurance markets to continue to function. In the developed world, the impetus and funding for adaptation will come primarily from national and local governments. With such a clear stake, the private insurance industry has an opportunity not only to contribute to the formulation of public policy on adaptation, but also to directly influence adaptation through its business practices. Both can be achieved through a combination of strategies, examples of which are outlined below. Such strategies not only incentivise and enable adaptation as an opportunity, but are themselves a necessity for ensuring the sustainability of weather-related insurance.

\section{Promote risk awareness and risk-reducing behaviour through risk-based pricing}

In principle, risk-based pricing is the practice of charging individual insurance policyholders premiums that directly reflect the risk of losses to which they are exposed (i.e. the technical risk price). In practice, premiums are based on a number of internal operational considerations, including the desire of insurers to make a profit, and external factors (e.g. competition among companies, regulation), so differences in premiums between policy-holders may not bear a direct relationship to the risks that are covered. ${ }^{14}$ However, risk-based pricing in the property and casualty market has the additional benefit that it provides an incentive to businesses and homeowners to limit or reduce the risks to which they are exposed in order to take advantage of lower premiums, as is observed in markets for other insurance products, such as automobile coverage.

\section{Develop insurance products and/or terms and conditions that incentivise risk reduction}

Risk-based pricing is one way in which insurance, a method of transferring risk, can be used to also reduce risks. There are other methods of bringing about risk mitigation, with both significant immediate and long-term benefits. For example, simple experiments with a catastrophe model can illustrate the loss reduction benefits of a

\footnotetext{
${ }^{14}$ Doherty et al. (2008).
} 
variety of adaptation measures including for flood, elevating the property or changing the property's characteristics (cladding, shutters, etc.) to improve flood resilience or resistance. The study performed by Lloyd's of London and RMS highlighted that adaptation to rising sea levels could reduce average annual losses from storm surge for individual properties in high-risk coastal communities in the 2030s to below presentday levels. ${ }^{15}$ In the case study for a property on the tropical Atlantic coastline, in the absence of adaptation, sea level rise alone increased 1 in 200 year losses by 20 per cent by the 2030s. In contrast, a simple adaptation measure, such as building a home on an elevated platform (between 0.5 and $1.5 \mathrm{~m}$ high), reduced losses to between 10 and 80 per cent below their present-day level.

While it is clear that risk mitigation measures reduce losses significantly, there are some barriers to their realisation, in terms of the magnitude of costs, who pays and who benefits. If adaptation measures are more expensive than the losses they are designed to prevent, it is likely that they will not appear cost-effective. While property and casualty insurers are primarily concerned with insured losses, cost-benefit calculations need to be rigorous and take into account uninsured losses (including those, such as social disruption, that cannot be directly costed in financial terms) and appropriate timescales.

In addition, insurers often argue that others, such as property-owners and governments, should bear the costs of risk mitigation measures. The willingness or capacity of insurers, property-owners and governments to pay for risk mitigation measures depends on the question of who accrues the benefit and over what period. It is well known that homeowners might be reluctant to invest significant sums in, say, strengthening their roofs against wind damage if the financial benefit is only realised over an extended period of lower premium payments, particularly if there is no longterm guarantee about the returns. ${ }^{16}$

There may be circumstances in which it makes financial sense for insurers to offer incentives, in addition to lower premiums, to policy-holders to invest in risk mitigation measures. However, the cost of offering such incentives to significant numbers of policy-holders will need to be considered alongside the likely benefits in terms of reduced losses within a portfolio.

Some property and casualty insurers do offer lower premiums, sometimes indirectly via discount and credit schemes, to policy-holders who invest in risk mitigation measures. For instance, MetLife and Allstate have reported incentivising customers to install storm shutters and other wind risk mitigation measures to make their homes more resilient to wind damage. ${ }^{17}$ A number of insurers in the United States are offering premium discounts for homes that follow the Institute for Business and Home Safety (IBHS) "Fortified ... for safer living" programme. Such premium discounts should not be arbitrary and should be informed by a quantification of the impact of the measures, for instance through the use of catastrophe risk models that can be employed with a specific building code standard or risk mitigation measure

\footnotetext{
${ }^{15}$ Lloyd's of London (2008).

${ }^{16}$ See, for example, Doherty et al. (2008).

17 Mills (2007).
} 
builtin. Insurers are unlikely to offer financial incentives, however, if they feel that policy-holders are already paying premiums that are low enough or too low (e.g. when the levels of premiums are set by regulators at a lower rate than insurers would like).

\section{Finance risk reduction/adaptation measures}

Larger insurers are in a position to directly finance customer-side adaptation measures that improve the resilience of properties to damage by weather hazards and thus reduce the risk of losses. These measures may not only make financial sense in terms of reducing direct losses. This could occur under some of the following circumstances:

1. An insurer associated with banking operations may offer preferential lending terms to policy-holders that have invested in measures to increase their resilience against the impacts of weather and climate change. Such a concept has already been applied to incentivise reductions in greenhouse gases (i.e. mitigation of climate change), including Fortis' preferential mortgage lending rates for energy efficient homes launched in 2006, and KBC Group's "Green Energy Loan" for homeowners making energy efficiency improvements.

2. Given a demonstrable financial benefit, a larger insurer could make a cost-benefit decision to invest in improving climate resilience as part of a premium service for its biggest clients. For example, AIG offers a premium wildfire protection service for its Private Client Group in which crews are deployed to apply fire retardant wherever policy-holders are threatened by wildfire in parts of California and Colorado. Such a solution has multiple benefits as the homeowner receives higher protection and the insurer may be able to avoid a large claim.

3. Banks with insurance operations may become involved in financing adaptation projects, in a similar manner to the increase in commercial funding for climate change mitigation.

4. Large insurers/reinsurers with substantial financial assets under management can make direct investments in adaptation projects and in emerging adaptation-related climate change funds. The insurance industry is the second largest industry in the world in terms of financial assets under management, and is well-placed to realise potential investment opportunities from climate change. Like any investments, those in climate change adaptation need to demonstrate attractive returns to investors. Insurers have already made direct investments in energy efficiency, renewable energy, forestry projects and green funds: for example, Allianz has committed to invest US\$350-\$600 million in renewable energy sources by $2010^{18}$ and Swiss Re closed its EUR 329 million European Clean Energy Fund in April 2007. Investments in adaptation could be targeted at firms, projects and funds related to water (e.g. technology, resource management and distribution), resilient infrastructure and sustainable agriculture.

\footnotetext{
${ }^{18}$ Mills (2007).
} 


\section{Offer climate change risk management/advisory services}

Insurers and reinsurers can harness their competencies in climate risk management and risk transfer to develop a variety of services that help businesses, investors and the public sector to adapt to climate change. Potential services include assessments of the physical risks from climate change, identification of priorities for risk mitigation, advice on risk transfer options and business continuity or disaster response planning. As an example, Zurich Australia announced in October 2008 that it will pilot a "Climate-Ready" programme - in conjunction with trained brokers - for small- and medium-sized enterprises to help them deal with the risks of climate change.

\section{Risk education}

Insurers can play a significant role in informing and educating customers about the risks of climate change that they face, and, importantly, about how best to reduce them. Many insurers have already been engaged in direct consumer (both homeowner and business) education activities on climate change adaptation. As an example of education aimed at businesses, Marsh, the largest insurance broker in the United States, began a programme with Yale University and CERES in 2007 to teach corporate board members about their fiduciary responsibility to manage their corporate exposure to climate change. ${ }^{19}$ Also, ClimateWise signatories have agreed to "supporting climate awareness amongst our customers" as one of five key principles guiding their actions and disclosures. For example, Co-operative Financial Services developed a Climate Change Tracker in collaboration with the U.K. Climate Impacts Programme (UKCIP) to illustrate to customers the likely changes in heat and rainfall in various parts of the U.K. in 2020, 2050 and $2080 .^{20}$

\section{Fostering disaster resilience practices and technologies}

The insurance industry has a history of fostering practices and technologies to reduce risk, through, for instance, innovations in building codes, vehicle safety and fire prevention. The industry likewise can enable and incentivise practices and technologies that help increase policy-holders' resilience to the impacts of climate change. Some examples include:

- Funding of independent research on climate risk mitigation and adaptation. For example, IBHS is funded in the United States by insurers and develops strategies and standards to improve the resilience of homes and businesses against weather hazards.

- Promoting adoption of improved building codes. A number of insurers have lobbied for the adoption of improved building codes. ${ }^{21}$

\footnotetext{
19 Mills (2007).

${ }^{20}$ Forum for the Future (2008).

${ }^{21}$ Mills (2007).
} 
- Advocating improved land-use planning. Planning of property development is a fundamental and effective tool for managing risk, and one which must not only incorporate increased consideration of information about weather hazards, but also the impacts of climate change over the lifetime of the planned infrastructure. Insurers can work in partnership with the public sector to determine appropriate planning policies. For example, in 2004, the Insurance Australia Group (IAG) worked with local government planners in New Zealand to provide risk modelling results to determine the most appropriate levels of flood planning for the future, which were subsequently incorporated within the flood mitigation programmes of local authorities. Likewise, recognising the value of retaining natural infrastructure, Tokio Marine Nichido has invested in the protection of mangrove plantations in Indonesia, Myanmar, the Philippines and Thailand, which reduce the risks posed by storm surges to areas further inland.

- Formulating multi-stakeholder adaptation principles. CERES and the Heinz Center launched a "Resilient Coasts" initiative in 2007 as a collaboration between private and public sector groups, including a few insurance sector participants, to produce a blueprint for coastal climate adaptation in the United States. Signatories to the initiative have agreed to implement, where possible, key principles contained in the blueprint in their own practices and to advocate their widespread adoption in other sectors. Recommendations from the project include: incorporate strong accountability standards and metrics in risk mitigation strategies and planning; require riskbased land-use planning; establish infrastructure standards to meet future risk; value naturally resilient infrastructure such as wetlands and barrier islands; strengthen building stock and revise building codes to hold new development to higher standards.

- Undertaking and disseminating research that highlights the cost-benefits of risk mitigation/adaptation. The joint project by Lloyd's of London and RMS quantified the impact of climate change on flood risk on individual properties at a number of coastal locations, and the benefits of a variety of adaptation measures, such as building flood defences, elevating property and changing the property's characteristics. $^{22}$

\section{Relationships with policy-makers, regulators, and other parts of the private sector}

The private insurance industry can play a leading role in guiding society's adaptation to the impacts of climate change, but this will require constructive relationships with policy-makers, regulators, public sector organisations and other stakeholders in the private sector. In most cases, these relationships can be improved by overcoming problems that currently beset these relationships. The following sections outline some of the key relationships.

\footnotetext{
${ }^{22}$ Lloyd's of London (2008).
} 


\section{Relationships with publicly-funded insurers}

Even where the private market offers insurance against weather hazards, there may be properties or individuals that are considered uninsurable. In many coastal States of the United States, the uninsurable can obtain coverage from publicly funded residual market insurers, or "insurers of last resort". In most cases, these publicly funded insurers do not compete directly against the private market companies, but instead provide a safety net that complements the commercial insurance sector. In the case of the National Flood Insurance Program, publicly funded insurance has completely replaced the private market, which withdrew during the 1920 s following concerns about the risk of correlated losses along major rivers.

Publicly funded insurers need to operate on different terms from the private market, not least because they offer a degree of subsidised coverage in order to make it more affordable to homeowners. Such subsidies have a particular disadvantage if they are offered through reduced premiums, which do not reflect the risk to which policyholders are exposed, and hence lower or eliminate the incentive to invest in risk mitigation measures. Subsidies also often mean that the publicly funded insurers do not have sufficient reserves to cover losses and may rely on other sources, such as public funds, in order to meet claims. These insurers also face other challenges, such as the limited geographical diversity of policyholders, increasing the risk of large spatially correlated losses.

As climate change could lead to a rise in the numbers of homes and businesses that are considered uninsurable against weather hazards by the private market, the role of residual market insurers is likely to become even more important. However, the current tensions that exist between the private insurance market and publicly funded residual markets need to be resolved, possibly through regulation that protects the long-term interests of consumers while promoting sustainability of insurance markets.

\section{Relationships with publicly funded reinsurers}

Climate change could increase the risk of very large losses from catastrophic weather events. One safeguard to protect against this could be the establishment of a topmost reinsurance layer which is provided by local or national governments, effectively capping the losses that could potentially be experienced by the private market.

In France, property insurance offered by the private market includes a mandatory extension to cover damage by natural hazards, including some extreme weather events. Insurers have the option of purchasing reinsurance from a publicly funded reinsurer, the Caisse Centrale de Réassurance (CCR). The French Government provides an unlimited guarantee to the CCR and hence meets claims that exceed the capital reserves of the $\mathrm{CCR} .^{23}$

In the United States, such arrangements exist for damage caused by acts of terrorism, introduced through the Terrorism Risk Insurance Act (TRIA) following the attacks on 11 September 2001. Similar arrangements have been discussed for the private market insurance against wind damage in coastal States. While, in the case of

\footnotetext{
${ }^{23}$ Marcellis-Warin and Michel-Kijan (2001).
} 
TRIA, the publicly funded reinsurance "backstop" is intended to complement private market reinsurance, some of the current equivalent and proposed arrangements for weather hazards in the United States seek partially to replace private reinsurers. In such cases, the main motivation appears to be to reduce the price of reinsurance cover for primary insurers, with the intention that this would lead to lower premiums for policy-holders. However, this may mean that the cost of reinsurance is subsidised, with the ultimate consequence that additional public funds are required to cover losses, as the risk is retained by national and local governments and not transferred into the global capital markets.

The relationship between private insurers and publicly funded reinsurers currently suffers in some countries, such as the United States, because of competing interests between the primary insurers and reinsurers. Greater recognition should be given by all parties to the dual needs of protecting the long-term interests of consumers and taxpayers, and of promoting the sustainability of insurance markets.

\section{Relationships with insurance regulators}

The relationships between private insurers and insurance regulators (and the policymakers who devise regulations) are often complex and it is beyond the scope of this paper to discuss all the ways in which climate change may have an impact on them. The National Association of Insurance Commissioners (NAIC) in the United States has provided an outline of some of the major challenges that climate change poses to regulation of the private market. ${ }^{24}$ One key issue is the question of how to manage the situation in which the affordability and availability of coverage changes as the risk of damage posed by weather hazards increases due to climate change. Although policies for property insurance are subject to annual renewal, the owners of homes and businesses usually expect a degree of stability in their contracts. Where risks from weather hazards increase substantially over short timescales, insurers may withdraw cover or increase premiums. Such changes, if introduced rapidly, for instance within the course of one round of renewals, can provoke negative public reactions, and policy-makers and regulators may be placed under pressure to limit the actions of insurers.

It is instructive to consider the lessons that may be learned from recent developments in the private insurance market for coverage against wind damage for homeowners in Florida. Following Hurricane Andrew in 1992, the private insurance industry realised that the risks of losses had been underestimated. Insurers attempted to immediately increase premiums to better reflect the risk to which properties in the State were exposed. However, policy-makers and regulators prevented sudden increases, and instead allowed premiums to rise steadily over a number of years. ${ }^{25}$ A similar situation has arisen in Florida over the past 5 years. Although the average annual frequency of hurricanes in the North Atlantic Ocean increased steeply after 1994, there was no immediate rise in premiums to reflect the increase in risk. However, after the record hurricane seasons of 2004 and 2005, insurers again tried to raise

\footnotetext{
${ }^{24}$ National Association of Insurance Commissioners (2008).

25 Pidot (2007).
} 
premiums, or to withdraw cover altogether from the most exposed properties, in Florida, but State regulators and policy-makers introduced a series of measures to limit the impacts on policy-holders. The lack of a constructive dialogue between the private insurers and the public authorities about how to respond to the change in risk has led to a perceived crisis in the homeowners insurance market. It remains to be seen whether premiums might be allowed to rise slowly in subsequent years. Better relationships between private insurers and the public authorities need to be developed if insurance is to play a role in helping property-owners in Florida, and other exposed areas, to cope with the impacts of climate change in the future.

\section{Relationships with property developers}

Even in the absence of any increases in weather hazards due to climate change, the risk of losses can rise if more businesses and homes are located in exposed areas. Such trends have been seen in many countries with established private insurance markets. High-risk locations, such as those on coastlines exposed to storm winds and surges or on low-lying land next to major rivers, are often considered to be desirable places to live and work because of their "natural beauty" and other factors. As a result, there are numerous examples where properties have been built in places that are already at high-risk of damage from weather hazards, or will be due to climate change, without consideration of whether they will be insurable now or in the future.

Property valuations in the United States, for example, tend to be unaffected by exposure to climate risks. Rather, the requirement is that the property is insurable at the time of purchase to enable mortgage-lending. Furthermore, hazard assessments that are carried out by developers, valuation professionals or financiers tend not to consider how risks might change over the lifetime of a property due to the impacts of climate change on weather hazards. As a result, the owners of homes and businesses may find that property insurance unexpectedly becomes unavailable or unaffordable, and their property value erodes.

At present, private insurers and reinsurers do not play a major role in decisions about the location of new properties, unless their own assets and investments are involved. There are clear benefits from the private insurance industry engaging in the decision-making process about future property developments, particularly for areas that might be affected by the impacts of climate change on weather hazards. In some cases, regulators assess development plans in terms of current risks from weather hazards, but potential insurability is not directly taken into account. Planning regulators should seek to engage the insurance industry in the decision-making process about developments in potentially exposed areas.

\section{Relationships with policy-makers}

An important example of a successful relationship between insurers and policy-makers is a voluntary agreement between the U.K. Government and the Association of British Insurers (ABI) on flood insurance. ${ }^{26}$ The U.K. is one of the few countries globally to

\footnotetext{
${ }^{26}$ Ward et al. (2008).
} 
have a private insurance market for coastal and inland flood risk. Flood insurance has been sustained in recent years through a voluntary agreement, known as the Statement of Principles, between the insurance industry (represented by its trade body, the ABI) and the U.K. Government. Under this agreement, the members of the ABI have committed to continue to make flood insurance available for domestic properties and small businesses where flood has an annual occurrence probability of lower than 1.3 per cent ( 1 in 75 years) and/or where the Environment Agency commits to reduce risk to below that level within 5 years. Alongside the Statement of Principles is an agreement that the U.K. Government will implement an investment plan for long-term flood management and ensure that planning regulations prevent inappropriate building in high-risk areas. The insurance industry and U.K. Government have also agreed to work together to improve understanding of flood risk, including making the public aware, and provision of information on ways to reduce risk and increase resilience. As part of this commitment, in 2008, the ABI published guidance on ensuring that new developments are insurable and increasing the resilience of homes to flooding.

Another example of a developing relationship between the private insurance industry and policy-makers is the Munich Climate Insurance Initiative (MCII), launched by Munich Re in April 2005 "in response to the growing realisation that insurance solutions can play a role in adaptation to climate change". The MCII has brought together representatives from the private insurance industry, academia, international agencies and non-governmental organisations. In December 2008, it published a document on an international insurance mechanism ${ }^{27}$ for the 14th Conference of the Parties to the United Nations Framework Convention on Climate Change (UNFCCC). The document responded to the "Bali Action Plan" that arose from the 13th Conference of the Parties, which called for "consideration of risk sharing and transfer mechanisms, such as insurance" to help developing countries to cope with the potential impacts of climate change.

The MCII provides an example of how the private insurance industry can engage more with the policy-making process on climate change, and decisions about societal adaptation to the impacts. However, there remains some concern among policymakers that insurance may reduce incentives to reduce risks. Proposals to extend insurance into developing countries need to be explicit about how insurance systems should be designed to complement rather than hinder disaster risk reduction efforts. In addition, those policy-makers that have been responsible for the provision of postdisaster aid have not always recognised the potential cost-effectiveness of ex ante mechanisms such as insurance. Further engagement is required between the insurance industry and policy-makers on all these issues.

\section{Corporate Social Responsibility - reputation reward and sustainable business practice}

There is a growing body of evidence about the business case for corporate social responsibility. ${ }^{28}$ Financial institutions are making increasing use of social criteria to

\footnotetext{
${ }^{27}$ Munich Climate Insurance Initiative (2008).

${ }^{28}$ For example, Porter and Kramer (2006).
} 
evaluate investments in companies, and there is strong evidence linking reputation with companies' abilities to command higher prices for their products and stock offerings. Demonstrating corporate responsibility can also aid a company's license to operate. For example, by taking substantive voluntary steps around tackling climate change risks, an insurer or reinsurer can persuade governments and the wider public that they are constructively confronting the issues of climate change. Building constructive relationships with policymakers, regulators and local communities in relation to climate change could limit suspicion and hostility relating to issues surrounding premium pricing in areas highly exposed to climate risks.

\section{Emerging insurance markets and developing world adaptation}

In the developing world, most of the world's population does not possess the means to insure themselves against weather hazards, or to invest in risk mitigation measures. These populations also tend to be the most vulnerable to weather risk today, and thus to the climate change impacts projected in decades to come. Financing adaptation in these regions will demand a high price tag - the necessary annual investment is estimated at between US\$28 and US\$67 billion by $2030 .^{29}$

Unlike in the developed world, the vulnerable countries in general are not rich enough to pay for adaptation. Help is needed from both the governments and the major global private sector companies in richer countries that have been mostly responsible for the elevated levels of greenhouse gases in the atmosphere today. The insurance industry, in particular, is uniquely positioned to play an important role, with its core expertise in quantifying, pricing, reducing and managing weather-related risks. Where and how insurers and reinsurers play a role in enabling adaptation in the developing world is both a corporate social responsibility for the global insurance industry, and also an opportunity for individual insurers and reinsurers to expand their markets, and develop new and innovative new products.

Key opportunities for the insurance industry relating to climate change adaptation in the developing world are outlined in the following sections.

\section{Risk education and fostering of disaster resilience}

Education to raise awareness of current and future risks can be a vital tool for disaster reduction in the developing world. It can enable risk-informed decision-making which can reduce potential damage and loss of life, shorten disaster recovery periods, and thus make local economies more resilient to climate risks. The international insurance industry can play a significant role in risk education, by developing local hazard and risk assessment capabilities in the developing world, disseminating information and by sharing best practice about risk management and mitigation with local communities, local insurance and micro-finance institutions, and local government. Such efforts not only demonstrate corporate responsibility, but act to improve the prospects for

\footnotetext{
${ }^{29}$ UNFCCC (2007).
} 
insurability of these regions, promoting expansion of risk-sharing initiatives, such as micro-insurance and catastrophe insurance pools.

\section{Current climate-related insurance products in the developing world}

Extending insurance cover to countries in the developing world will not only support economic progress and poverty alleviation in these regions, but can also enable disaster-prone nations to manage growing risks from weather hazards. Insurance is already and increasingly playing a role in some areas of developing countries. Publicprivate pilot initiatives are demonstrating to local populations and governments the benefits of pooling weather risks and transferring them to the global insurance markets, and of paying a little in advance for protection from extreme events that can destroy livelihoods. A few examples include:

- Micro-insurance, including climate-index-based insurance products. An increasing number of insurers and reinsurers are offering micro-insurance products related to weather risk, which in the developing world is most needed to cover agriculture and food-related risk, rather than for risks to properties. In particular, demand is growing for index-based climate risk micro-insurance programmes as an alternative to traditional crop insurance. These instruments are linked to the underlying weather risk defined as an index (based on historical weather data, e.g. for rainfall, temperature) rather than the extent of loss (e.g. crop yield loss). As an example, Swiss Re has helped to pioneer these instruments in low income countries, including a collaboration in India with a micro-finance institution and a local insurer which has to date sold 350,000 policies to smallholder farmers in India since 2007. Swiss $\mathrm{Re}$ has also designed and implemented index based weather risk transfer instruments for three village clusters in Kenya, Mali and Ethiopia ${ }^{30}$ protecting 150,000 farmers against drought risk, as part of its Climate Change Adaptation Program. The MCII has also been responsible for education within the insurance industry of such opportunities and the associated challenges.

- Climate-index-based insurance products for governments. These products are also of interest in cases where the insured is a government, rather than an individual farmer. For example, in 2006 the World Food Programme (WFP) piloted an index-based drought insurance scheme for government relief expenditure in Ethiopia with AXA Re. In the event of a drought, Axa Re would have paid \$7.1 million to WFP, which would have been transferred subsequently to the Ethiopian government for distribution as cash assistance to householders. Even though the 2006 pilot did not result in a payout because there was sufficient rainfall, the programme was deemed a success by WFP due to its innovative approach to risk management. Future transactions may include a catastrophe bond, which pays an above-market interest rate if rainfall exceeds a specified level, but if rainfall is lower, part of the principal would go to the Ethiopian government.

\footnotetext{
${ }^{30}$ Osgood et al. (2007).
} 
- Multi-country insurance risk pools. As an example the Caribbean island states in partnership with the World Bank recently formed the world's first multi-country index-based catastrophe insurance pool, the Caribbean Catastrophe Risk Insurance Facility (CCRIF), to provide governments with immediate funds following hurricane or earthquake catastrophes.

While these examples highlight the opportunities for new risk transfer schemes in developing countries, there are also major challenges that must nevertheless be considered. These include: difficulties in quantifying risk due to limited reliable data, limited financial infrastructure, low familiarity with insurance, and limited purchasing power to cover the cost of insurance.

New markets: developing world insurance as part of an international climate change deal

Financing methods for adaptation in developing world countries is currently a key subject of negotiation among the Parties to the United Nations Framework on Climate Change Convention (UNFCCC). Issues under discussion include the origin of funds, and importantly from the perspective of the private insurance industry, how to allocate these funds in developing countries which often lack the required financial infrastructure (i.e. a banking and insurance system) and governance, to help manage climate risks and losses.

Insurance itself has been mentioned in several places in the agreements of the climate negotiations, in the Bali Action Plan (BAP) which calls for "consideration of risk sharing and transfer mechanisms, such as insurance" to address the losses of developing countries particularly vulnerable to climate change. At the 14th Conference of the Parties to the UNFCCC in Poznan, Poland, insurance was one of the major items of discussion on the adaptation agenda. National Parties expressed significant interest in the potential of insurance, and agreed that insurance tools would be needed to incentivise risk reduction and that the private insurance sector should be involved. By the 15th Conference of the Parties in Copenhagen in December 2009, it is expected that Parties will have designed the overall architecture of a post-2012 climate agreement, which would be an international law that could potentially outline the role of insurance, the associated international funding for such schemes, and the related engagement by the private insurance sector with climate change adaptation in the developing world.

\section{Conclusions}

In this paper, we have explored the implications of climate change adaptation for the private insurance industry, both in terms of the threats to commercial success from not responding adequately to the need for adaptation, and the opportunities that arise from playing a role in the global response to this pressing issue. We highlight how the physical impacts of climate change can affect the day-to-day operations and the longer-term strategic direction of insurers and reinsurers. We also demonstrate that climate change adaptation will be relevant to both the underwriting and investment operations of larger companies. 
The main conclusion is that companies can minimise the threat and maximise opportunities from the physical impacts of climate change by ensuring that their decision-making, business practices and strategies are resilient to climate change. Furthermore, activities that incentivise and enable adaptation not only give rise to opportunities, but are increasingly necessary for the sustainability of the industry. While opportunities for investment and underwriting related to climate change mitigation (e.g. coverage for, or investment in low-carbon technologies) have thus far received the most attention, there is clearly a fundamental business and societal role for the industry to play by leading on adaptation.

\section{References}

ABI (2005) 'Financial Risks of Climate Change', www.abi.org.uk/Display/File/Child/552/Financial_Risks_ of_Climate_Change.pdf.

Doherty, N.A., Grace, M.F., Klein, R.W., Kunreuther, H.C., Michel-Kerjan, E.O. and Pauly, M.V. (2008) 'Managing Large-scale Risks in a New Era of Catastrophes: Insuring, Mitigating and Financing Recovery from Natural Disasters in the United States', Wharton Risk Management and Decision Processes Center, http://opim.wharton.upenn.edu/risk/library/Wharton_LargeScaleRisks_FullReport_2008. pdf.

Forum for the Future (2008) 'Climate Wise: One Year Review', www.climatewise.org.uk/storage/ climatewise-docs/ClimateWise\%20Independent\%20Review\%202008.pdf.

Grossi, P. and Kunreuther, H. (eds) (2005) Catastrophe Modelling: A New Approach to Managing Risk, Springer: New York.

IPCC (2007) 'Climate change 2007: The physical science basis', in S. Solomon, D. Qin, M. Manning, Z. Chen, M. Marquis, K.B. Averyt, M. Tignor and H.L. Miller (eds) Contribution of Working Group I to the Fourth Assessment Report of the Intergovernmental Panel on Climate Change, Cambridge, UK and New York, NY, USA: Cambridge University Press.

Kunreuther, H. and Pauly, M. (2009) Insuring against catastrophes, working paper \#2009-04-13, Wharton Risk Management and Decision Processes Center, http://opim.wharton.upenn.edu/risk/library/WP20090413_ HK,MP_KuU.pdf.

Lloyd's of London (2008) 'Coastal Communities and Climate Change: Maintaining Future Insurability', part of the 360 Risk Project www.lloyds.com.

Marcellis-Warin, N.de and Michel-Kerjan, E. (2001) 'The Public-Private Sector Risk-Sharing in the French Insurance "Cat. Nat. System", Centre interuniversitaire de recherché en analyse des organisations www.cirano.qc.ca/pdf/publication/2001s-60.pdf.

Mills, E. (2007) 'From Risk to Opportunity: 2007', Insurer Responses to Climate Change, A CERES-Report, Boston.

Munich Climate Insurance Initiative (2008) 'International Insurance Mechanism: A Proposal for the Copenhagen Agreed Outcome, Version 3.0', http://unfccc.int/resource/docs/2008/smsn/ngo/078.pdf.

National Association of Insurance Commissioners (2008) 'The Potential Impact of Climate Change on Insurance Regulation', www.naic.org.

Osgood, D.E., McLaurin, M., Carriquiry, M., Mishra, A., Fiondella, F., Hansen, J., Peterson, N. and Ward, N. (2007) Designing Weather Insurance Contracts for Farmers in Malawi, Tanzania, and Kenya, Final Report to the Commodity Risk Management Group, ARD, World Bank, New York, USA: International Research Institute for Climate and Society (IRI), Columbia University.

Pidot, J.R. (2007) Coastal Disaster Insurance in the Era of Global Warming: The Case for Relying on the Private Market, Washington, USA: Georgetown Environmental Law \& Policy Institute and Georgetown University Law Center.

Porter, M.E. and Kramer, M.R. (2006) 'Strategy and society: The link between competitive advantage and corporate social responsibility', Harvard Business Review, December, http://hbr.harvardbusiness.org/ 2006/12/strategy-and-society/ar/1. 
Sullivan, R., Russel, D. and Robins, N. (2008) Managing the Unavoidable: Understanding the investment Implications of Adapting to Climate Change, Henderson Global Investors, USS, Railpen Investment Insight Investment. January 2008. www.usshq.co.uk/downloads/pdf/all_sections/ri/managing_the_unavoidable. pdf.

Swiss Re (2005) 'Innovating to insure the uninsurable', Swiss Re Sigma Series, 4/2005 www.swissre.com/ resources/1340e800455c566c9753bf80a45d76a0-sigma_4_2005_e_rev.pdf.

Swiss Re (2006) 'Natural catastrophes and man-made disasters 2005: high earthquake casualties, new dimension in windstorm losses', Swiss Re Sigma Series, 2/2006, www.swissre.com/resources/ e109a780455c56b897efbf80a45d76a0-Sigma2_2006_e.pdf.

UNFCCC (2007) Investment and Financial Flows to Address Climate Change, Bonn, Germany: UNFCCC.

Ward, R.E.T., Herweijer, C., Patmore, N. and Muir-Wood, R. (2008) 'The role of insurers in promoting adaptation to the impacts of climate change', The Geneva Papers on Risk and Insurance - Issues and Practice 33(1): 133-139.

\section{About the Authors}

Celine Herweijer is a Director in the PwC U.K. Sustainability and Climate Change team, based in London. Celine joined PwC from Risk Management Solutions (RMS), a catastrophe modelling company, where she was the Director and Principal Scientist of the RMS Climate Change team. Celine holds a PhD in Climate Modelling from Columbia University, New York.

Nicola Ranger is a Research Fellow within the Centre for Climate Change Economics and Policy (jointly funded by the ESRC and Munich Re), part of the Grantham Research Institute on Climate Change and the Environment at the London School of Economics. Nicola joined LSE from Risk Management Solutions. She previously held positions as a policy analyst for the (now) U.K. Department of Energy and Climate Change and on the Stern Review on the Economics of Climate Change. She holds a $\mathrm{PhD}$ in Atmospheric Physics from Imperial College London.

Robert E.T. Ward is Policy and Communications Director at the Grantham Research Institute on Climate Change and the Environment at the London School of Economics and Political Science. He joined the Institute in November 2008 from Risk Management Solutions, the catastrophe modelling company, where he was Director of Public Policy. 